\title{
As ações sociais da Irmã Serafina Cinque na Transamazônica (1970-1979) e as aproximaçôes teóricas de Paul Ricoeur sobre o sentido de esperança
}

\author{
Sister Serafina Cinque's social actions in the Transamazônica (1970-1979) and Paul Ricoeur's theoretical \\ approaches to the sense of hope
}

Léia Gonçalves de Freitas*

Irlanda do Socorro de Oliveira Milée**

Francilene de Aguiar Parente***

Palavras chave:

Esperança

Existência humana

Ações Sociais

Keywords:

Hope

Human existence

Social actions

\begin{abstract}
Resumo: Este estudo buscou identificar o sentido da esperança expressa nas açôes sociais desenvolvidas pela Irmã Serafina Cinque na Transamazônica na década de 1970 a partir das aproximaçóes teóricas sobre o sentido de esperança refletida à luz de Paul Ricoeur. Nos interessou investigar qual o sentido da esperança nas ações sociais voltadas às mulheres grávidas realizadas pela Irmã Serafina Cinque na Transamazônica, no Município de Altamira- PA e como esse trabalho se articula com as discussões teóricas ricoeuriana. Os caminhos metodológicos utilizados foi a pesquisa documental com abordagem qualitativa, fundamentado em Ricoeur nas obras "História e Verdade” (1968) e “o Conflito das interpretações” (1999); as fontes foram: acrósticos, poesias, literatura de cordel e Relatórios de Atividades (1970 - 1979) das açôes de Irmã Serafina Cinque. Os resultados evidenciaram que o sentido da esperança para Ricoeur $(1968$; 1999) é um esperar, mas também um caminhar rumo à liberdade; a esperança como paciência de esperar, aguardar o livramento e a libertação chegar. E, para Irmã Serafina Cinque a esperança é uma espera de transformação social e de libertação.
\end{abstract}

\begin{abstract}
The Transamazonica highway is 50 years old. By delimiting this period, the text exposes to interested readings five possible parties of its history. Certain that a reliable portrait of its trajectory is infactible in History studies, we assume the deliberate selection of episodes found in consulted sources and documents, so that we could somehow represent the countless faces of such an object. We started with the prefix "trans" as a device for interpreting the word "transamazônica". When determining such a prefix as an enhancer of meanings, we can identify other qualities and understandings for this road than just a transport infrastructure. The Transamazônica highway is, above all, an action, surrounded by innumerable attributes: is to transfigure by symbologies, it is to go through scales, it is to transform by technification, it is to show through utopian landscapes, it is upsetting by the invisible. They are portraits of a highway that the forest, in its own way, managed to tame. But until when?
\end{abstract}

Recebido em 15 de junho de 2021. Aprovado em 15 de outubro de 2021.

\footnotetext{
* Professora Doutora em Educação, Universidade Federal do Pará/Campus Universitário de Altamira/Faculdade de Educação. E-mail: leiafreitas@ufpa.br.

** Professora Doutora em Educação, Universidade Federal do Pará/Campus Universitário de Altamira/Faculdade de Etnodiversidade. E-mail: irlanda@ufpa.br.

*** Professora Doutora em Antropologia, Universidade Federal do Pará/Campus Universitário de Altamira/Faculdade de Etnodiversidade. E-mail: faparente@gmail.com.
} 


\section{Introdução}

Este artigo objetiva identificar o sentido da esperança expressa nas açóes sociais desenvolvidas pela Irmã Serafina Cinque na Transamazônica na década de 1970 a partir das aproximações teóricas sobre o sentido de esperança refletida à luz de Paul Ricoeur. Nosso problema de pesquisa busca refletir qual o sentido da esperança nas ações sociais voltadas às mulheres grávidas efetivadas pela Irmã Serafina Cinque na Transamazônica, no Município de Altamira-PA e como esse trabalho se articula com as discussóes teóricas ricoeurianas? Esse sentido impacta o itinerário filosófico dos trabalhos realizados pela Irmã Serafina Cinque, no tocante às interfaces socioeducativas e políticas da assistência e proteção à infância em Altamira-PA?

O Caminho metodológico adotado foi a pesquisa documental com abordagem qualitativa, acrescida de revisão bibliográfica analisada à luz de Paul Ricoeur (1968; 1997; 1997; 1999). O documento é a prova material das evidências, daí ser necessário assegurar a sua autenticidade, confiabilidade e qualidade. Sua procedência deve ser verificada, assim como as intençôes de seus autores, a natureza do texto, os conceitos chave e a lógica interna da escrita.

Em relação às fontes, os documentos estudados foram acrósticos, poesias, literatura de cordel, relatórios de atividade e plano de aplicação encontrados no arquivo particular da Congregação das Adoradoras do Sangue de Cristo, da qual integrava Irmã Serafina Cinque. Dois arquivos foram pesquisados: 1) Casa Divina Providência em Altamira Pará; 2) Sede da Congregação em Belém, capital do estado do Pará. Em relação às fontes documentais da Casa Divina Providência, tivemos acesso aos acrósticos, poesias, literatura de cordel, que descrevem e contam a história da instituição religiosa, caritativa e filantrópica, integrante das Obras Sociais da Prelazia do Xingu - Congregação da Igreja Católica, desde 1934, quando foi desmembrada da Arquidiocese de Belém-PA.

A Casa foi fundada em 1972, pela religiosa Serafina Cinque, da Congregação das Adoradoras do Sangue de Cristo, e tem como filosofia educacional a Pedagogia do Amor, cujos princípios "visava à formação da criança, do jovem e da mulher no plano natural, atingindo toda a sua espiritualidade moral social e religiosa e fundamentava-se na essência dos ensinamentos de Jesus e no seu amor fortalecido pela cruz" (OLIVEIRA, 2005, p. 67).

As bases teóricas da Pedagogia do amor das Adoradoras baseavam-se na Pedagogia do Amor criada por Johann Heinrich Pestalozzi, em 1798, cujos trabalhos tiveram início com a educação dos órfãos e desabrigados. $\mathrm{O}$ método pedagógico, baseava-se na bondade, no amor, na fraternidade, na igualdade e na liberdade, defendendo a ideia de que a educação visava formar o educando em seu desenvolvimento cognitivo, afetivo e espiritual; já os fundamentos pedagógicos das Adoradoras, pautava-se no bem e no amor caridoso (FREITAS, 2019).

$\mathrm{Na}$ sede da Congregação das Adoradoras do Sangue de Cristo, tivemos acesso aos Relatórios de Atividade da Casa Divina Providência do ano de 1979, apontando que se trata de uma entidade confessional vinculada à Igreja Católica, que ao longo dos anos vem se dedicando à assistência, proteção e à educação da mulher e da criança pobre, abandonada e órfấo na Transamazônica.

O Objetivo da Casa é "receber as mães gestantes doentes ou não, que moram nas vicinais $\mathrm{da}$ Rodovia Transamazônica, nas Colônias e nas áreas ribeirinhas, independente de raça e credo, que vem dar à luz ao seu bebê" (RELATÓRIO DE ATIVIDADE, 1979, p. 1). Com essa intenção, essa instituição acolheu, ao longo desses anos, mulheres grávidas, que em sua maioria, chegavam desnutridas, com malária, hepatite, anemia profunda, verminose, albumina e doenças venéreas, em carência total, situações essas que se estendiam aos recém-nascidos. A Casa da Divina Providência fazia acolhimento também aos portadores de doenças infectocontagiosas, fruto da realidade tão dura e desafiante da região (RELATÓRIO DE ATIVIDADE, 1979).

Amor, caridade e justiça social foram discursos eminentes nas ações da religiosa, bem como a existência de uma prática libertadora no atendimento aos oprimidos; trabalhos sociais que eram desenvolvidos com os objetivos de proporcionar um sentimento de esperança no tocante à garantia de direitos da assistência e 
proteção aos mais empobrecidos, ideal filosófico e pedagógico da Congregação. Esses ideais fundamentaram-se na Pedagogia do Amor, vislumbrando o "viver a partir da realidade do Evangelho uma educação comprometida com a organização, participação, reflexão e solidariedade” (RELATÓRIO DE ATIVIDADE, 1979, p. 2).

A dimensão social desta pesquisa se pauta na reconstrução da memória documental como fonte histórica, rica em informações e grandeza de detalhes, especialmente se considerarmos a década de 1970 como um marco na vida da sociedade altamirense. Época em que a visita do presidente Emílio Garrastazu Médici ao município de Altamira selou a fase inicial da construção de uma das maiores rodovias federais do país, Rodovia BR-230, conhecida como Transamazônica.

A rodovia teve como monumento inaugural uma placa fixada a uma castanheira, conhecida popularmente como "pau do presidente". Nela está cravado o texto: "nestas margens do Xingu, em plena selva amazônica, o Senhor Presidente da República dará início a construção da Transamazônica, numa arrancada histórica para a conquista desse gigantesco mundo verde" (PLACA INAUGURAL, 1970).

Segundo Freitas (2019), no decorrer do processo de abertura da rodovia Transamazônica, Altamira se destaca entre os municípios que atraíam muitas pessoas e se transforma na "Princesinha do Xingu", ou mesmo na "Capital da Transamazônica", como ficou popularmente conhecida. Milhares de famílias chegavam à procura de terra e de dias melhores. Os comerciantes locais sonhavam com muito dinheiro a ser derramado na pequena cidade da Amazônia paraense. Os fazendeiros e os grandes latifundiários exploravam mão de obra barata dos nordestinos, provindos geralmente do Ceará e do Maranhão, à procura de trabalho e de um lugar para morar e construir sua vida.

Como diz Kräutler (2005), era o "Eldorado do Xingu”. O governo investia em propagandas de progresso e modernidade, incentivando o processo migratório de nordestinos e sulistas. A Amazônia aguardava para ser explorada, habitada e civilizada. Nesse ideal de civilização, também estava posto o de modernização das cidades e de higienização.

Por isso, era preciso investir em uma empreitada governamental que divulgasse o discurso da boa moradia e da farta qualidade de vida em lugares ventilados, arborizados, com altos índices de plantaçôes naturais, o que proporcionava ao povo ar puro e benefícios ambientais inigualáveis, contudo, se a propaganda oficial mostrava a heroica conquista do território, de progresso a todo custo e de uma arrancada e acelerada modernidade dos espaços, a realidade daqueles anos de construção provocou efeitos intensos na vida dos que viviam na região antes da construção da estrada e daqueles que vieram para trabalhar nela (FREITAS, 2019).

Esses efeitos foram evidenciados na sociedade altamirense, sobretudo, à infância, que de acordo com Freitas (2019) enfrentaram problemas relacionados à privação de direitos de assistência, proteção e educação. As infâncias amazônicas são múltiplas e articulam-se às complexas redes de relações formadas por pessoas, lugares, tempos, atividades, papéis e instituições, mediadas por normas, crenças e valores do grupo social aos quais os sujeitos estão inseridos, possibilitando-nos capturar os muitos fios tecidos na construção da sua identidade.

Tais fundamentos subsidiam a compreensão de infância, partindo do pressuposto de que os processos vivenciados se tornam a base para as experiências subsequentes, principalmente se foram consolidados em um alicerce estável por tempo prolongado, como se deu com as crianças de Altamira na década de 1970, que viviam em constante situação de violação de direitos. Neste contexto, as ações sociais da Irmã Serafina Cinque, surge como raios de esperança para os mais empobrecidos, em especial, para as mulheres grávidas que viviam ao longo da Transamazônica.

Estruturalmente, esse artigo se divide em duas seçóes, na primeira apresentamos a as vivências experienciadas pela religiosa na Transamazônica, fundamentada no aporte teórico e metodológico da Pedagogia do Amor, buscando problematizar o sentido de esperança para Irmã Serafina Cinque e sua articulação com as discussóes ricoeurianas. $\mathrm{Na}$ segunda seção, apresentamos as açôes de assistência, proteção e educação à infância pobre, abandonada e órfã na Casa Divina Providência, instituição fundada e dirigida pela Irmã Serafina Cinque, na Transamazônica, nos idos de 1970 a 1979. 


\section{Irmã Serafina Cinque e o sentimento de esperança: diálogo com Paul Ricoeur}

Serafina foi professora dedicada, competente enfermeira e ser humano sensível às causas sociais. Multiplicava-se no atendimento aos pobres, às mulheres desassistidas e à infância órfã e desvalida. Em uma regiáo onde faltava médico, ela foi enfermeira; onde faltava advogada, ela foi defensora dos direitos dos excluídos; onde faltavam políticas sociais, implantou a equipe social e promoção humana. Sabia bem o que fazer quando era solicitada. Tinha saberes instrumentais e humanos adquiridos nos tempos de formação de professora que cursara em 1933 e no curso de enfermeira prática em 1943, ambos ocorridos na cidade de Manaus - Amazonas; e no curso de formação teológica em 1947, realizado nos Estados Unidos (MENEZES, 2008).

Os saberes de Irmã Serafina Cinque cotidianamente eram postos à prova. Todos os dias era um recomeçar, uma nova luta. E, ao assumir uma história de empoderamento social e político junto aos excluídos de Altamira, Transamazônica e Xingu, expunha toda a sua experiência com a vida humana. Confrontava-se com a ambiguidade do progresso e das catástrofes sociais da década de 1970, um período com tantas turbulências econômicas, políticas, ideológicas, sociais e culturais.

Saberes que para Ricoeur (1968, p. 83), refletem produçôes humanas, ou seja, é "tudo quanto o homem aprendeu, tudo quanto ele sabe, tudo aquilo que ele sabe pensar, dizer, sentir e fazer, tudo isto é adquirido" e se sedimenta, estratifica, ganha vida e acumula-se nas açóes práticas do cotidiano social, político e educacional dos sujeitos. Esses cotidianos são produzidos nas atividades experienciadas a partir de entendimentos historicamente vivenciados, especialmente em um período cujo progresso significava civilização - "uma maneira temporal de projetar um estilo concreto de existência, de querer de homem" (RICOEUR, 1968, p. 88). Seria isso a dissimulação da humanidade?

Para Ricoeur (1968) a humanidade passa pelas civilizaçóes e estas nascem e morrem. Ao mesmo tempo podemos ter uma concepção cíclica e uma concepção linear do progresso. No primeiro caso, temos um nível mais ético, no outro, o nível mais técnico. Mas, em ambos os casos, é preciso encontramos o centro do processo histórico para dar sentido à condição humana, visto ser "a humanidade promovida, instituída, educada pela política” (RICOEUR, 1968, p. 125).

Irmã Serafina Cinque, acreditava nisso, tanto que o princípio ético do sentido da esperança que trazia em suas açôes sociais não se esgotava com a crise dos períodos históricos, com a grandeza dos fatos e nem com a culpabilidade mesclada. $\mathrm{O}$ sentimento ético de esperança que movia a religiosa era o amor. Amor profundo devotado aos pobres. Ela compreendia que o "amor não prejudica $o$ próximo. O Amor é pleno cumprimento da lei” (RICOEUR, 1968, p. 124), destarte, não se podia então deixar de doar amor. Mesmo sendo "o progresso o que há de racional na história [...] e a esperança o sentido supra-racional, da maneira que se diz, surrealista" (RICOEUR, 1968, p. 95).

Era movida por sentimento amor-esperança, que com persistência e humildade, a pé ou de carro; de noite enfrentando duro açoite, quer da chuva, quer do sol quente, procurava soluçóes e, abrir corações para a gestante sem atendimento. "Quantas vezes enfrentou poeira, chuva, indiferença, Transamazônica, doença. Mas nunca se abateu. Trazia no coração a chama viva do amor. Distribuía carinho para quem só conhecia a dor" (MENEZES, 2008, p. 5).

A religiosa não se eximia da responsabilidade de assistir e proteger o povo sofrido que vivia entre a injustiça e a violência de um local esquecido. Lutava contra o poder e a tirania em prol da gente desvalida. "Contra a cultura da morte Serafina foi mais forte lutando em favor da vida!” (SIQUEIRA, 2001, p. 29).

O nome de Serafina cruzou a Transamazônica, ela foi pioneira no atendimento das grávidas e dos excluídos, mas foi na infância que, com extrema dedicação e ações, ficou conhecida nas cidades, campos, matas e rios. A doação de Irmã Serafina Cinque não se esgotou nas obras de sua missão, dava conselhos aos jovens, aos adultos e aos cristãos. Estes eram seu querido próximo - "a maneira pessoal pela qual eu encontro o outro, para além de toda mediação social; [...] não sendo definitivamente reconhecida pelos próprios atos exteriores, mas será revelada no último dia, com a 
maneira pela qual terei, sem o saber, encontrado Cristo" (RICOEUR, 1968, p. 102).

Nos idos de 1970 a 1979, Irmã Serafina vai assistindo e protegendo a vida cotidiana das mulheres grávidas e crianças órfãs e desvalidas. Aos poucos, a vida dessas mulheres e crianças eram preenchidas de amor e esperança. Esperança "enquanto prática que exige completude; mas ela crê, a maneira da espera, da esperança, na existência de uma ordem onde esta completude pode ser efectiva”. [...] (RICOEUR, 1999, p.409).

Esperança como fonte de libertação dos cansados e oprimidos. Libertação que só ocorre no embate da luta. Libertação como liberdade humana. Mas, o que é a liberdade sustentada pela esperança? Para Ricoeur (1970, p. 688) a liberdade é aquilo que ele chamou de "duplo limite: o limite de meu conhecimento, e o limite de meu poder. Por um lado, não conheço a origem de minha liberdade má; por outro lado descubro a falta-de-poder de minha liberdade".

O entendimento de liberdade aqui é transgressão à norma; a esperança é um esperançar, um caminhar rumo à libertação (FREIRE, 1992). De qualquer modo, a liberdade se constitui como algo extremamente difícil, por isso deve ser sustentada pela esperança. É ela que possibilita condiçôes para que os sujeitos vislumbrem a dignidade ameaçada e agredida. É a partir dela que a liberdade se torna necessária e recobra o ânimo de lutas por direitos negados. Mas ainda, mesmo não sendo o mundo a pátria definitiva da liberdade, a esperança consiste em resgatar desse mundo uma nova liberdade (RICOEUR, 1968). Sendo irracional, ela [a liberdade] nasce da provação e no interior dos conflitos, dos sofrimentos, da provação e dos dramas sociais, assim, existe apesar do sofrimento, para além do desespero.

Racionalmente, a lei da superabundância é afirmada na lógica do amor, concretizando-se pela gratuidade e pelo perdão (RICOEUR, 2012), do sentido sobre o não sentido, porque a esperança é paciência de esperar, aguardar o livramento e a libertação chegar. É esperançar - um processo de acontecer.

A partir das próprias experiências, Irmã Serafina vai se debruçando para aquilo que julgava necessário, assistir e proteger à mulher grávida e à infância pobre; vai conquistando liberdade humana e as cadeias vão sendo quebradas, para criar um lugar de respeito permanente e conhecimento de si-mesmo e do outro.

As condições sociais e políticas vão sendo resgatados e os aportes pedagógicos e filosóficos conquistados, assim, fundamentada na Pedagogia do Amor, a religiosa foi ao longo da década de 1970, intensificando suas ações práticas e se afirmando no cenário altamirense, imbuída de sentimento de justiça social, participando do cotidiano dos oprimidos, incitando discussões e reivindicações de ordem econômica, política, cultural e social do período. São açóes com aportes metodológico, eclesiológico, político e da espiritualidade, imbuídas dos princípios do amor, da caridade e da justiça social para pobres.

No nível metodológico, as ações da religiosa assumiam uma mediação sociopolítica mais plural, da prática cotidiana do olhar sensível do Outro; no nível eclesiológico, o trabalho se voltava mais para as Comunidades de Bases e havia maior liberdade para se debater temas sobre o papel social da Igreja, religião popular, fé e política, mídia, movimentos sociais e realidades urbanas. Em relação ao nível político, a prioridade pautava-se em discussóes voltadas para o atendimento dos excluídos (caridade e assistência), situação propícia para as alianças e acordos que visavam o bem comum e; no nível da espiritualidade, o centro do debate era a mística de Deus, seu amor e seu ensinamento como reflexão para a simbólica luta de classes (FREITAS, 2019).

A partir do mandamento do amor como caridade, as açóes socioeducacionais da religiosa tiveram como lema "o espírito é todo amor e toda caridade” (OLIVEIRA, 2005, p. 21). Com efeito, a caridade é para a Pedagogia do Amor a ordem infinitamente mais elevada. Nas palavras de Ricoeur (2012, p. 5):

[...] de todos os corpos juntos não se pode fazer resultar um pequeno pensamento: é impossível, e de outra ordem. De todos os corpos e espírito, não se podem extrair um movimento de verdadeira caridade, é impossível, e de outra ordem, sobrenatural (RICOEUR, 2012, p. 5). 
A caridade exalta o amor como virtude ascendente ao amor a Deus e ao querido próximo. Amor sublime, encantamento difícil de ser explicado. O amor, ah, o amor! Ele é eletrizante e provoca em nós reaçóes que se manifestam nos olhos e em todo o corpo (RICOEUR, 2012). É descoberta do outro, é inexprimível e retórico, metafórico. É poesia. Amar é romper barreiras, costumes, leis e rotinas sociais que prejudicam o próximo querido. É tomar parte do sofrimento do outro como sendo o si do outro. É a sublimação da alma, do imaginário, do sentir-se amada. Enfim, amor é doação (RICOEUR, 2012).

O amor é divino, humano e caridoso (RICOEUR, 1999), ideal propagado na filosofia educacional da Pedagogia do Amor, vivenciado nas ações sociais da religiosa simbolizado no sentido de caridade e amor, manifestado na lógica do dom e do sentimento de esperança (OLIVEIRA, 2015).

Serafina era a esperança dos oprimidos, cuidava junto às autoridades de enterros de pobres e desassistidos; ajudava aos doentes, especialmente, tuberculosos e hansenianos; socorria os idosos, muitas vezes, abandonados; e recolhia e tratava de mulheres grávidas e crianças órfãs e desvalidas. Ela derrubava estereótipos que reduzia e limitava o pensamento humano sobre a esperança, ao memo tempo em que transgredia as normas ao rebelar-se e buscar a promoção da liberdade e do conhecimento.

Conhecedora dos princípios pedagógicos $\mathrm{e}$ filosóficos da Pedagogia do Amor, que defendia os ensinamentos pautados no binômio amor $\mathrm{e}$ caridade, a religiosa cotidianamente se afirmava como acalento dos oprimidos como demonstrado nos trechos do poema "Irmã Serafina Cinque: "O Anjo da Transamazônica” de Antônio Juraci Siqueira (2001), ao registrar em versos as atitudes de respeito, afeição, trabalho e compromisso da religiosa com os povos da Transamazônica, em plena Ditadura Militar:

Migrantes de toda parte por todo canto se via, plantando sonho e esperança, às margens $\mathrm{da}$ rodovia. O progresso propalado nos ditos $\mathrm{da}$ Ditadura foi aos poucos, se tornando semente de desventura.

Comparada à bomba atômica a estrada Transamazônica tornou-se Transamargura. Foi nesse campo minado por tanta desigualdade que nossa Irmã Serafina e a sua comunidade, lutaram bravamente para atender tanta gente que chegava na cidade.

Do malfadado projeto foi a miséria um produto. $\mathrm{Na}$ cidade de Altamira esse crescimento bruto transformou-se num tumor traduzido em muita dor, desavença, pranto e luto (SIQUEIRA, 2001, p. 16).

Serafina era sinônimo de doação ao Outro, aquele de quem nos aproximamos e de quem nos tornamos próximos. Tornar-se próximo é, para Ricoeur (2004), uma reponsabilidade ética, ação de solicitude. A lógica do dom se articula com o caráter unilateral e bilateral do amor, pois, em verdade, o funcionamento da lógica do dom não está na "coisa dada, mas na relação doador-recebedor" (RICOEUR, 2004, p. 8). Desse modo, o reconhecimento mútuo da ação se configura pelo próprio ato do dom, visto ser a supremacia do amor a generosidade oferecida no dom inicial e não "exigência de equivalência e de retribuição" (RICOEUR, 2004, p. 8). Ao doar-se aos pobres e oprimidos Serafina, simbolicamente, trocava gratidão, alegria do reconhecer e ser reconhecido, estimado e querido (RICOEUR, 2004).

A sabedoria do amor de Irmã Serafina tem a intencionalidade de fluir no outro a percepção da alteridade. Assim, na relação com o outro considera, justamente, a bondade, o respeito e o amor como sentimento. $\mathrm{O}$ encontro com o outro - que sofre é, por consequência, a manifestação do simples amor como disposição do amar. Neste interim, o que está em jogo é a sensibilidade humana, alicerçada na sabedoria do amor e da caridade. Trata-se se perceber o outro, como alguém que está disposto a ensinar o que é o amor, seja como louvor ou como obrigação. De qualquer maneira, o amor é uma aceitação pessoal, mas nem por isso é solitário. Não há amor sem socialização, logo, o amor é um fenômeno social. Quando ocorre a aceitação do outro ou o ato da doação (lógica do dom), há socialização e, por conseguinte, humanização. Isso significa que para Ricoeur (2012), o amor humaniza o homem.

É no domínio do amor que a caridade se fundamenta e, para Serafina, esse amor vinha de Deus. Toda sua vida e obra era toda bondade. 
era como que uma repetida, afetuosa e sempre reconhecida manifestação da gratidão amorosa que crescia cada vez mais em seu coração diante da constatação da bondade de Deus em cada ocorrência de sua vida. "Como Deus é bom", com esse lema, agradecia a Deus e ajudava a todos. [...] Tinha um grande espírito de sacrifício e doação. Esquecia-se de si para ajudar os outros (ADORADORAS DO SANGUE DE CRISTO, 2007, v. V, p.10).

Esse amor se espalhava pela comunidade, pela cidade, pela Congregação e por toda sua obra socioeducativa. Era um amor que acolhia, protegia e educava mulheres grávidas e lhes davam um parto humanizado, como identificado nos Relatórios de Atividade de 1979, que registrava a política social da Casa Divina Providência.

\section{Política Social da Casa Divina Providência e suas repercussões no cenário transamazônico}

A primeira sede surgiu em 1972, na Rua 1o de Janeiro, no centro da cidade de Altamira. Esse espaço foi cedido pela Prefeitura Municipal, e servia de acolhimento dos doentes graves e gestantes em perigo, que vinham dos travessóes da estrada da Transamazônica e Xingu. Todavia, os registros documentais apontaram que sua origem se deu quando, certo dia, uma senhora grávida recebeu alta do Hospital São Rafael. Sentindo-se fraca, sem assistência e direcionamento sobre o que fazer, procura Irmã Serafina que, ao vê-la, acolheu-a já desmaiada. Improvisou um leito para ela; de repente, a pequena sala teve que acolher dez outras senhoras, que se encontravam na mesma situação (RELATÓRIO DE ATIVIDADE, 1979).

Com o decorrer do tempo, o espaço ficou sem condiçôes de habitação e higiene e por isso um segundo local precisou ser instalado. A nova sede estava localizada na Travessa Comandante Castilhos, parte central da cidade, onde também faltavam alimentos e suporte necessário para atender a demanda. Como essa também não comportava os atendimentos, Serafina começa a receber muitas críticas da comunidade local e da própria Prelazia.
Com tenacidade, ela procura outro alojamento para as gestantes, crianças e doentes. Assim, a terceira casa é conseguida na própria Travessa Comandante Castilho, hoje número 190, atual sede da Empresa Brasileira de Pesquisas Agropecuárias - EMBRAPA (RELATÓRIO DE ATIVIDADE, 1979).

No ano de 1977 , a terceira sede da casa não comportava os abrigados e outro local precisou ser providenciado temporariamente, até a construção da sede definitiva. Assim, após anos de luta, inicia-se a construção da Casa Divina Providência. A parceria veio da Prelazia do Xingu. Dom Eurico Kräutler, junto ao Governo de Vorarlberg, na Áustria, e amigos de uma Paróquia de Biberach, no Sul da Alemanha, conseguiram doaçóes para a tão sonhada obra. Em 1979, à Rua Antônio Vieira, bairro de Brasília, ergue-se a Casa, que foi inaugurada em 1984. Padre Frederico Tschol projetou e foi incansável durante a construção, com o objetivo de a deixar funcional para os fins desejados (RELATÓRIO DE ATIVIDADE, 1979).

$\mathrm{Na}$ Casa Divina Providência, mesmo no seu início, "as mulheres não iam para lá apenas para ter seus bebês, todavia, adquiriam conhecimentos que lhes melhorassem a vida" (ADORADORAS DO SANGUE DE CRISTO, 2007, v. III, p. 10). Recebiam educação entendida na sua forma mais ampla - como prática social, como cultura, "como prática criadora, que visa a levar o ser humano a realizar suas potencialidades físicas, morais, espirituais e intelectuais" (BRANDÃO, 2007, p. 63). Educação como processo contínuo que abrange o ser integral, pois ela existe sob tantas as formas, em diferentes contextos e situações que muitas vezes, parece invisível.

$\mathrm{Na}$ Casa Divina Providência, a educação era o "resultado da ação de todo o meio sociocultural sobre seus participantes. É o exercício do viver e conviver o que educa” (BRANDÃO, 2007, p. 47). Desse modo, durante o período que antecedia a chegada dos bebês, o que às vezes durava várias semanas, e no período após o parto, dependendo do estado de saúde das mulheres, elas recebiam formação religiosa, moral, higiênica e profissional materializada em cursos sobre trabalhos manuais, medicina caseira, orientação religiosa, aleitamento materno, pré-natal, espaçamento entre uma gestação 
e outra, prevenção de doenças, alfabetização por meio do método freiriano.

Educacionalmente, essas mulheres aprendiam "misturadas com a vida em momentos de trabalho, de lazer, de camaradagem ou de amor" (BRANDÃO, 2007, p. 17). Mas, também, trocavam saberes experienciais que fluíam pelos atos, de quem sabe-e-faz, ensina-e-aprende. Essa troca de aprendizado acontecia na Casa, por meio de relaçóes dialógicas, observaçóes livres e dirigidas e conversação, cujo objetivo era fazer surgir novas formas sociais de condução do processo de aprender-e-ensinar.

Todo trabalho conduzido era pautado, preferencialmente, nas formas livres, familiares e ou comunitárias de educação. Porém, ideais higienistas e princípios religiosos eram também existentes e comuns, no programa de educação da Casa Divina Providência. Assim, quando a Casa ensina às mães a forma correta de cuidar e educar os filhos, realizava educação. Como importante espaço de formação doméstica, religiosa, social e moral dos sujeitos, essa instituição, enquanto ação caritativa, acolheu e educou a mulher e a infância e, ao mesmo tempo em que disciplinava, buscava desenvolver novos conhecimentos, habilidades e atitudes a partir de princípios cristãos. Centrou suas açôes na integridade do ser moral, pois, como ser moral, o sujeito é aquele que se orienta, "que se agarra e se mantém no espaço moral; e a consciência, a este primeiro nível, pelo menos, não é outra coisa senão esta orientação, este agarrar-se e este manter-se [aceito]" (RICOEUR, 1995, p. 187). Explanatoriamente, pelo viés da política higienista, a Casa atendeu diferentes sujeitos desvalidos, formou bons hábitos, instruiu e educou "essa gente boa" pobres, que ameaçavam à Doutrina Segurança Nacional e as Políticas de Assistência (FREITAS, 2019).

Neste momento, a preocupação da Casa Divina Providência era prestar assistência e proteção às mulheres grávidas da cidade e do campo. Devido à mobilidade urbana, as mulheres citadinas eram a maior demanda de atendimento da instituição. Todavia, as grávidas lavradoras, que morriam sem qualquer assistência, porque ficavam cuidando de suas terras e dos produtos, esperando a hora de vendê-los, para irem à cidade dar à luz aos seus filhos sem quaisquer assistências. Pensando nessa situação recorrente, a Irmã Serafina Cinque viu que "se houvesse parteiras nos ramais, dentro da Estrada, muitas crianças não morriam” (SUPER ... vol. III, 2007, p. 7).

Em parceria com o Serviço de Saúde Pública do Pará, a religiosa oferta aulas a 700 mulheres, a quem o povo chamava de "curiosas", preparando-as para a responsabilidade do parto (RELATÓRIO DE ATIVIDADE, 1979). Essa atitude melhorou a sorte das grávidas e parturientes do campo, já que houve arrefecimento nos atendimentos entre os anos de 1976 e 1978.

Durante o ano de 1977, o total de atendimento foi de 332 gestantes, dentre elas, 08 senhoras conceberam natimorto. Isso se deve em parte às visitas domiciliares realizadas pelas "parteiras"; a doação de medicamentos pela Casa em parceria com a Prelazia às enfermas e à concessão de vale transporte às mulheres grávidas moradoras $\mathrm{da}$ zona rural. Ao final, os investimentos totalizaram um montante de $16.809,00$ mil cruzeiros (RELATÓRIO DE ATIVIDADE, 1979).

No ano de 1978, a Casa atendeu 248 gestantes, desse quantitativo, nasceram 233 crianças vivas e 15 natimortos. A mortalidade, segundo o Relatório de Atividade, se deu devido à debilidade de suas mães que não tinham condiçóes de vir do interior até a cidade para fazer o pré-natal ou uma consulta médica. Também foram atendidas 312 crianças para consultas e tratamento de saúde (RELATÓRIO DE ATIVIDADE, 1979).

Em 1979, a casa acolheu 330 gestantes. Desse total, 278 deu à luz, sendo 271 vivos e 07 natimortos. Houve ainda registros de 03 abortos. As 49 grávidas a mais, vieram para tratamento de saúde. Dos 281 nascimentos, 210 foram normais e 71 partos Cesário, com a incidência de 03 crianças gêmeas (RELATÓRIO DE ATIVIDADE, 1979). A despeito das grávidas urbanas, registramos a existência dos Projetos: "Clube de Mães" e o de "Alfabetização de Jovens e Adultos". O primeiro era financiado pela LBA, que investia mensalmente um valor de 15 mil cruzeiros nas obras sociais, os demais recursos advinham da Prelazia do Xingu. O projeto em 1973, contou com mais de mil membros que participavam ativamente das aulas de bordado, pintura, corte e costura, horticultura, palestras 
educativas curso de educação doméstica. A partir dos cursos ofertados, o projeto Clube de Mães objetivava "melhorar o nível socioeconômico das associadas e sua participação na vida grupal” (RELATÓRIO DE ATIVIDADE, 1973, p. 1).

No decorrer de 1973, o projeto contou com a parceira de duas extensionistas, uma da Associação de Crédito e Assistência Rural do Pará (ACAR-PA), outra das Cáritas Brasileira. Ao final do ano, foram confeccionados enxovais para os bebês da Casa Divina Providência; abertura de poços (cacimba) para as residências carentes; doação de filtros de barro para água; registro de nascimento e realização de casamentos. Nos anos de 1976, o projeto recebeu mais 150 gestantes, que participaram das atividades desenvolvidas.

Concomitante, ao programa de confecção de enxovais, ocorreram encaminhamentos das grávidas para o serviço de Pré-Natal, constante de consulta médica e exames e medicamentos, quando necessários, ao Hospital São Rafael e ao Ambulatório João XXIII.

Em 1973, esteve vinculado este ano ao projeto um médico, duas enfermeiras, duas extensionistas da ACAR-PA, três instrutoras voluntárias e uma auxiliar social. Os investimentos de recursos chegaram a 25 mil cruzeiros, $15 \mathrm{mil} \mathrm{da}$ LBA e 10 mil da Prelazia do Xingu (PLANO DE APLICAÇÃO, 1976, p. 2).

No ano de 1977, foram atendidas 250 grávidas adultas, 300 crianças de até doze anos de idade e 300 adolescentes doentes e algumas grávidas. Entre as crianças, atenderam-se órfầs (PLANO DE APLICAÇÃO, 1977, p. 2).

No ano de 1978, o projeto atendeu 750 mulheres participantes dos cursos e palestras e grávidas menores de 18 anos. Para esse atendimento, a turma foi dividida em cinco grupos: o primeiro grupo foi formado de 400 grávidas que compôs o programa de enxovais; o segundo correspondeu a 337 crianças e adolescentes para aquisição do registro de nascimento; o terceiro grupo foi formado por 50 participantes aptos para o casamento; o quarto foi o grupo responsável por promover as atividades culturais com um total de 144 participantes. O quinto grupo foi o de palestras educativas de formação moral e religiosa e cursos profissionalizantes, composto por 669 mulheres (PLANO DE APLICAÇÃO, 1978, p. 1).

$\mathrm{O}$ projeto de "Alfabetização de Jovens e Adultos" adotava a metodologia cunhada por Paulo Freire (1981), que afirmava que a educação pode ser libertadora e opressora. O que as distingue, é a intenção do trabalho educativo desenvolvido. Como libertadora, a prática educativa tem o poder de transformar geraçóes, que uma vez potencializada pela formação, se colocará como sujeito ativo no mundo. Mas não se trata de qualquer ensino, qualquer conteúdo, ela aposta em uma educação popular, cuja prática garante aos sujeitos, pelo saber-fazer cotidiano, a valorização de si, dos seus saberes e suas identidades culturais (FREIRE, 1981). Segundo os dados do Plano de ação Pastoral da instituição de 1979, a cada 30 gestantes participantes das aulas, cinco foram alfabetizadas e saíram aptas para leitura e escrita. As demais assinavam o nome e lia pequenas frases (PLANO DE AÇÃO PASTORAL, 1979).

Esse tipo de metodologia dotada pela Casa se assemelha segundo (ROSEMBERG, 2016) com a metodologia de trabalho entendida como Desenvolvimento de Comunidade, por se tratar de ações com participação social. Os significados atribuídos a tal organização tiveram presente nos discursos da prevenção, com conotaçôes eugênicas, visto que a LBA orientava suas atividades e seus recursos "na defesa de nossa raça, cuidando das mães e das crianças, os homens de amanhâ" (ROSEMBERG, 2016, p. 218); posteriormente, sua ação visou evitar a mendicância e a vadiagem, tendo na profissionalização a possibilidade de desenvolvimento da Nação. No pensamento de Rosemberg (2016), os eventos e projetos gestados pela LBA adotaram as mesmas estratégias da Doutrina de Segurança Nacional e do Desenvolvimento de Comunidade, tendo na participação comunitária, redução de custos.

Em Altamira, a LBA foi parceira da Casa Divina Providência ao destinar recursos para o Projeto Clube de Mães, que previa ações educativas às grávidas e à infância de forma direta, visando capacitar as mulheres empobrecidas para a vivência social e profissional.

Outra finalidade da Casa era formar boas mães. Nos lembra Freitas (2019) que os discursos 
apontados nessas açôes eram de que as mulheres deveriam ser educadas porque geravam o embrião da sociedade. Portanto, seu comportamento e atitude deveriam ser revistos, pois mulheres bem instruídas são capazes de melhor criar, cuidar e educar seus filhos.

Evidenciamos um processo de molde não apenas da mãe, mas, em longo prazo, da infância. Era um ideário de sujeito sendo pensado e construído pela Igreja e pelos religiosos, que, influenciados por discursos higienistas "salvavam" moral e eticamente a criança, sujeito esquecido pelas autoridades políticas e jurídicas "que não via a criança como sujeito em si, mas na perspectiva de concretude e perfeição para o futuro: o adulto do amanhâ" (GUIMARÃES, 2016, p. 88).

"Ao educar a mãe educava-se o filho" (RELATÓRIO DE ATIVIDADE, 1979, p. 3). Esses discursos, de unidade mãe-filho como foco de atenção médica, colocam as crianças como sujeito biopolítico da nação; à mulher é dado o lugar de reprodutora e a responsabilidade pela educação e criação dos filhos, idealmente fortes, saudáveis e úteis para o bem do país e para o progresso da nação.

Em Altamira, esses discursos se unem aos de higienização da urbe, justificando, assim, a nosso ver, uma das prerrogativas para a criação da Casa Divina Providência - embora não a mais importante, visto que seu objetivo geral era dar assistência e proteção às mulheres grávidas que, sem ter para onde ir, desamparadas e expostas a todo tipo de perigo, se refugiavam neste local.

Por conseguinte, recebiam ensino moral, religioso e profissional fundamentado em modernos princípios higiênicos voltados para a formação da mulher como boa mãe de família e uma boa cidadã. Ao serem retiradas das ruas, essas grávidas não perambulavam como mendigas, não gatunavam e evitavam a perversão, a vadiagem e, o pior, a morte.

A Casa Divina Providência, neste ponto de vista, era um espaço privilegiado para a formação da mulher, pois legitimava escolhas e condutas, civilizava e salvava a criança. Salvar, neste caso, significa modificar seu comportamento, moldar. Para Rizzinni e Schueller (2011, p. 71): "[...] uma ação de intenso investimento na fase da infância fazia sentido dentro de um arcabouço ideológico subjacente ao projeto civilizatório, pois se acreditava que a criança tanto poderia ser moldada para tornar-se virtuosa quanto viciosa”.

Como alvo, a educação doméstica atingia a família e a criança, que, educada corretamente, seria sociável e útil à sociedade, cabendo à mulher o papel dessa educação. Percebe-se essa situação nos documentos da Casa Divina Providência, os quais apontam que o cuidado com a saúde das grávidas, parturientes e recém-nascidos era detalhadamente prescrito. $\mathrm{O}$ serviço de enfermagem era fundamental nesse processo e as intervenções médicas e odontológicas e indicaçóes farmacêuticas se materializavam em discursos higienistas ao pretenderem formar um determinado padrão de sujeito para um "cenário político que buscava a inserção do país como nação civilizada [...] favorável às ações de saúde pública" (PACHECO, 2017, p. 69).

Constituir o problema da saúde e da educação como uma questão local "funcionou como uma espécie de exorcismo de angústias alimentadas" por melhores condiçóes de vida para essas mulheres e suas famílias, pois as existentes na região postulavam efeitos nocivos à população, tornando-as "infundadas para as esperanças de progresso para o Brasil” (CARVALHO, 2016, p. 411).

À vista disso, as açóes socioeducativas e protetivas da Casa Divina Providência estavam carregadas de discursos ideológicos, que buscavam intervir na saúde e prescrever práticas saudáveis de comportamentos às abrigadas.

Ao examinar as grávidas e encaminhá-las ao tratamento conveniente, ao prepará-las para o parto, ao dar assistência ao berçário e ao fornecer orientação sobre medicina caseira e uso de medicamentos, essa instituição buscava intervir na saúde de mãe-filho, pois estes precisavam estar fortes e saudáveis, longe de quaisquer doenças ou problemas que pudessem colocar em risco a capacidade institucional de cuidar e educar.

Entretanto, esta não era uma premissa para Serafina, tampouco se prendia ao puro ideal $\mathrm{da}$ política higienista da época. Ela era transgressora quando o assunto era assistir e proteger as mulheres grávidas pobres e carentes. "Tinha grande amor à Igreja, ao Papa e à Congregação com profundo senso de pertença. Porém, era firme em não deixar que pequenas leis de estrutura comunitária derrubassem 
a suprema lei da caridade e de amor ao próximo” (ADORADORAS DO SANGUE DE CRISTO, 2007 , v. V, p. 13). E a quem não compreendia os excessos de sua obra para com as gestantes, ela explicava: "a situação das mulheres pobres é muito difícil, não é fácil evitar filho!” (ADORADORAS DO SANGUE DE CRISTO, 2007, v. IV, p. 8).

Para Irmã Serafina, a situação da mulher grávida era para além das convenções religiosas da constituição familiar. Seu amor e luta em favor dessas mulheres não era uma luta apenas social, mas um "compromisso particular para sensibilizar os ricos em favor dos pobres, e as autoridades políticas para que essa porção do povo não fosse abandonada” (ADORADORAS DO SANGUE DE CRISTO, 2007 , v. II, p. 462). Essas mulheres, geralmente, eram mães de duas ou mais crianças, nem sempre com a presença paterna, ou seja, eram "famílias incompletas" (PUEBLA, 1979), muito presentes na região naquele dado momento.

Esse era o diferencial de Serafina, o divisor de águas. Pensamos que, apesar do entrelaçamento da Pedagogia do Amor e da política higienista, posta em sua obra, sua grande contribuição para região era exatamente seu deslocamento formal de princípios norteadores que oprimem e censuram.

Sua mente era livre; para ela não havia distinção de raça, cor, religião ou posição social. Não via complexidade na sua atividade socioeducativa, pois interpretava tudo pelo amor, caridade e justiça social. A despeito de incompreensões e insensibilidade humana por parte de alguns religiosos e da sociedade, que, por vezes, não reverenciava sua ação, Serafina "ao socorrer ao pobre [a grávida], não se limitava a satisfazer as exigências do momento, mas procurava promover a pessoa, torná-la autônoma, livre, restituir a sua dignidade e esperança" (ADORADORAS DO SANGUE DE CRISTO, 2007, v. II, p. 462).

\section{Pontuando algumas considerações}

Irmã Serafina Cinque, às vezes nos confundia com tanto zelo, paciência e caridade genuína. Mãe dos pobres e doentes acolhia sua gente de vida tão marginal, dava banho e medicava, resgatava a autoestima e alimentava a alma com luzes divinal.
Era um encontro com o querido próximo, com o carente e com os desprovidos de justiça.

Em Altamira, era por conversas formais e informais que Irmã Serafina Cinque instigava as pessoas a um novo olhar sobre o exercício da liberdade como suporte para justiça. Seu desejo era a possibilidade de renovação, não só do sistema político e da sociedade como um todo. Mas era sabedora que sozinha não mudaria a estrutura do sistema. Mesmo assim, sua esperança na existência humana era maior e, em meio a essas açôes, estimulava os excluídos a valorizar o que podem controlar (sua política de assistência e proteção à infância).

Seu sentimento não era de culpa por não conseguir libertar a todos dos paradigmas de uma sociedade cética e exploradora, mas de esperança e felicidade em ver a vida de mulheres, homens, jovens, especialmente de crianças, caminhando em direção às conquistas importantes tais como: direito à educação, à saúde e à moradia. Dessa relação dialógica sobressaia uma reflexão que implicava um ato constante de conhecimento social e posicionamento crítico frente à realidade.

Ao debruçar-se sobre a realidade exigia das mulheres atendidas na Casa novas posturas políticas e sociais; reverberava vozes esperançosas de participação social e comunitária buscando mitigar discursos higienistas voltados para a formação e orientação moral e religiosa priorizando a adequação de comportamentos sociais.

Se por um lado, os discursos higienizadores perpassavam as práticas cotidianas da instituição destinadas às grávidas, abordados nos eixos:

1) da saúde - unidade mãe-filho, visando proporcionar bem-estar, segurança e conforto por meio de ações de orientação materno-infantil e atendimento pré-natal;

2) e no eixo da ação social, com a finalidade de formação sanitária, doméstica e social, por meio de cursos de curta duração como aulas de trabalhos manuais (tapeçaria, bordado, pintura, crochê e costura), palestras, orientação familiar e vivência comunitária;

3) e nos eixos da educação religiosa, que priorizava a formação moral e cristã, visando combater vícios oriundos da má formação social e dos maus hábitos domésticos. 
Por outro, os discursos de esperança como prática de liberdade materializado nas ações de Irmã Serafina e na política social da Casa Divina Providência resultou em importantes medidas de assistência e proteção à infância ao conferir às mulheres pobres e silenciadas, oportunidade de vivenciar novas experiências comunitárias, sociais e política cujo entendimento pauta-se no cuidar, educar e evangelizar como processos indissociáveis.

No projeto de Alfabetização, por exemplo, as vivências dessas mulheres eram discutidas no contexto do Método Paulo Freire, que defende uma educação emancipadora, promotora de conhecimento crítico para a compreensão da realidade e para a transformação social, cuja prática garante aos sujeitos, pelo saber-fazer cotidiano, a valorização de si e do outro - ponto de aproximaçóes teóricas entre os sentimentos de esperança de Irmã Serafina e Paul Ricoeur.

Para ambos a esperança realiza o encontro do eu com o si-mesmo e revela a dimensão do ser humano nas suas mais extensas necessidades de autoconhecimento pessoal. A esperança é um processo de completude do ser, uma condição da existência humana, por isso, o homem precisa se autoconstruir enquanto agente de transformação social, pois, é na esperança que o eu-dos-atos, se encontra com o si-mesmo. Por ela o homem se move e se supera. Ela é a responsável por fazer brotar no íntimo do homem a sensibilidade do direito à liberdade e à libertação do corpo e da alma. Mas ao fazer isso, o homem também reconhece a si-mesmo e a outrem; reconhece seu direito e o direito alheio. Sai da subserviência.

\section{Referências}

ADORADORAS DO SANGUE DE CRISTO, Super vida, virtudes e fama de santidade. Roma, 2007. 7 vols (livros).

BRANDÃO, Carlos. Rodrigues. O que é educação? São Paulo: Brasiliense, 2007.
CARVALHO, Marta Maria Chagas de. Quando a história da educação é a história da disciplina e higienização das pessoas. In: FREITAS, Marcos Cezar de (Org.). História Social da Infância no

Brasil. São Paulo: Cortez, 2016. p. 395-416.

FREITAS, Léia Gonçalves. Políticas de assistência, proteção e educação à infância pobre, abandonada e órfã e as ações da Prelazia do Xingu no município de Altamira - Pará (1970-1979). 2019, 262 f. Tese (Doutorado em Educação) - Programa de Pós-Graduação em Educação, Instituto de Ciências da Educação, Universidade Federal do Pará, Belém, 2019.

FREIRE, Paulo. Pedagogia do Oprimido. 17 ed. Rio de Janeiro: Paz e Terra, 1981.

FREIRE, Paulo. Pedagogia da Esperança: reencontro com a Pedagogia do Oprimido. Rio de Janeiro: Paz e Terra, 1992.

GUIMARÃES, Jaqueline Tatiana da Silva. Os discursos dos médicos do Estado do Pará nas teses de doutoramento ou inaugurais (1929-1954): saúde, assistência e educação da infância pobre. 2016, 320 f. Tese (Doutorado) Universidade Federal do Pará, Belém, PA, 2016.

KRÄUTLER, Erwin. Mensagem de Abertura. In: SEVÁ FILHO, A. Oswaldo (Org.). Tenotã-mõ: alerta sobre as consequências dos projetos hidrelétricos no Rio Xingu. São Paulo: International Rivers Network, 2005. p. 9-12.

MENEZES, Marília. O Anjo da Transamazônica: Irmã Serafina Cinque, ASC. Belém, 2008.

OliveIRA, Maria Clemes. Maria de Mattias como eu vejo. Belém, PA, 2005. 
OLIVEIRA, Ivanilde Apoluceno. Diretrizes metodológicas freireanas e a educação jurídica popular. Revista InSURgência, Brasília, DF, v. 1, n. 1, p. 16-31, jan./jun. 2015.

PACHECO, Tatiana do Socorro Corrêa. Infância, crianças e experiências educativas no Educandário Eunice Weaver em Belém do Pará (1942-1980). 2017, 250 f. Tese (Doutorado) Programa de Pós-Graduação em Educação, Instituto de Ciências da Educação, Universidade Federal do Pará, Belém, PA, 2017.

PLACA inaugural do marco da Transamazônica. Altamira, 1970.

PLANO DE AÇÃO PASTORAL DA CASA DIVINA PROVIDÊNCIA. Altamira, 1979.

PLANO DE APLICAÇÃO. Clube de Mães. Altamira, 1976; 1977; 1978.

PUEBLA, Documento. Evangelizacão no presente e no futuro da América Latina: conclusóes da III Conferência geral do Episcopado Latino-americano. Texto Oficial. Puebla de los Angeles, México, Edições Paulinas, 1979. Disponível em: http://portal.pucminas.br/imagedb/documento/D OC_DSC_NOME_ARQUI20130906182452.pdf. Acesso em: 30 nov. 2018.

RELATÓRIO DE ATIVIDADE, Casa Divina Providência. Altamira, 1973.

RELATÓRIO DE ATIVIDADE, Casa Divina Providência. Altamira, 1979.

ROSEMBERG. Fúlvia. O LBA, o Projeto Casulo e a Doutrina de Segurança Nacional. In: FREITAS, Marcos Cezar de (Org.) História Social da
Infância no Brasil. São Paulo: Cortez, 2016. p. 205-228.

RIZZINNI, Irene; SCHUELLER, Alessandra. O instituto do Prata: índios e missionários no Pará (1898-1921). Currículo sem Fronteiras, v. 11, n. 2, p. 86-107, jul./dez. 2011.

RICOEUR, Paul. História e verdade. Trad. F. A. Ribeiro. Rio de Janeiro: Forense, 1968.

RICOEUR, Paul. Culpa, ética e religião, In: Concilium: Revista Internacional de Teologia. Petrópolis, v. 07, fas. 56, 1970, p. 688.

RICOEUR, Paul. O Justo ou a essência da justiça. Trad. Vasco Cassimiro. Lisboa: Instituto Piaget, 1995.

RICOEUR, Paul. Tempo e narrativa. Vol. III. Trad. Roberto Leal Ferreira. Campinas, SP: Papirus, 1997.

RICOEUR, Paul. O conflito das interpretações: ensaios de hermenêutica. Trad. CORREA. M. F. Sá. Porto, Portugal: Rés, 1999.

RICOEUR, Paul. A luta por reconhecimento e economia do Dom. Trad. Cláudio Reichert do Nascimento e Noeli Dutra Rossatto. Paris: Unesco, 2004.

RICOEUR, Paul. Amor e Justiça. Trad. BRANDÃO. Eduardo. São Paulo: WMF Fontes, 2012.

SIQUEIRA. Antônio Juraci. Irmã Serafina Cinque, o Anjo da Transamazônica. Literatura de Cordel. Belém, 2001. 